\title{
City Pulse: Supporting Going-Out Activities with a Context-Aware Urban Display
}

\author{
Mohammad Obaid $^{1,2}$, Ekaterina Kurdyukova ${ }^{2}$, and Elisabeth Andre ${ }^{2}$ \\ ${ }^{1}$ HITLab New Zealand, University of Canterbury, Christchurch 8140, New Zealand \\ ${ }^{2}$ University of Augsburg, Universitätsstr. 6a, 86159 Augsburg, Germany \\ mohammad.obaid@hitlabnz.org, \\ \{katja.kurdyukova, andre\} @informatik.uni-augsburg.de
}

\begin{abstract}
In this paper, we describe a concept of City Pulse, an urban public display that helps people find going-out locations of their taste. Relying on mobile context collected by going-out citizens, the display visualizes the immediate situation in city locations. The sensors integrated into the citizens' mobile phones gather data on people's motion, pulse, and sound around. Based on this data, City Pulse display shows, for instance, how crowded and how loud the locations are, which music is playing, whether people dance or drink. In addition, users can request the display to highlight the places matching their preferences, such as specific cuisine or music style. It also allows finding locations where the user's friends are currently going out. We present design and of City Pulse display, motivating the concept by the user study conducted with 20 international participants.
\end{abstract}

\section{Motivation}

The advent of Web 2.0 [1] has significantly improved the way people plan their leisure time activities. Relying on the user-generated content, such as online forums, eased and diversified the way we choose the locations for travelling, sightseeing or going out. In this work we focus on going-out activities in public locations, such as bars, cafés, restaurants, clubs, or discos. A public display reflecting the current situation in city locations can solve the problem. In this work we present City Pulse, an urban public display that visualizes the immediate situation in city locations. The display relies on real-time context data provided by the visitors of city locations. The context data is implicitly collected from sensors integrated into mobile phones of visitors. The data collected from numerous visitors going out in the city, is reflected by the display content.

Considering people as ubiquitous sensors, "People are eight billion sensors" [2], enable modern technology to collect and generate large amounts of urban data. Such user-generated data can be used to understand and improve the situation in the cities.

Most work doesn't rely on real-time information but rather on the analysis of previously collected data, e.g. [3]. Often there is a necessity to have an urban picture based on real-time information. 
City Pulse display, presented in this paper, utilizes various mobile sensors to collect the data on immediate situation in the city. Collecting the data on people's motion, pulse, location, and loudness, it visualizes the current situation in going-out locations.

\section{City Pulse Design}

City Pulse is designed based on the insights gained from interviewing 20 participants, where the aim was to capture criteria to decide on the going-out location, difficulties people have when looking for a location, and their vision of the City Pulse display. The semi-structured interviews were conducted individually, in a form of a moderated discussion.

We designed the visualization of City Pulse display to provide two views: standard and personalized view. The standard view presents the data critical for the majority of people (based on interviews). The opened locations are overlaid over the city map covering the neighborhood areas. For each location the display shows the density of people, loudness, people motion (dancing, standing or sitting), and alcohol consumption. The design is illustrated with the example, Figure 1, of downtown Munich, Germany.

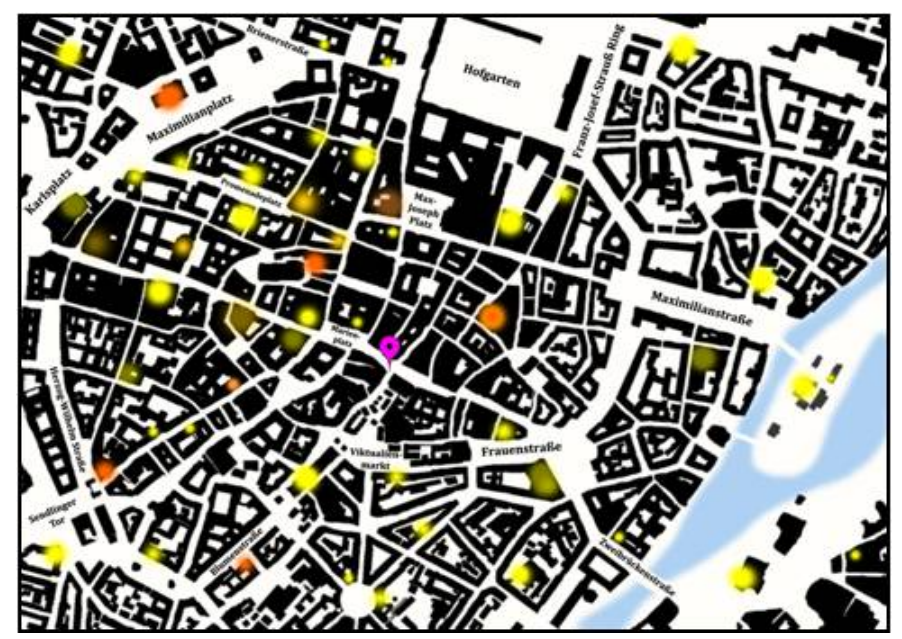

Fig. 1. City Pulse display: downtown Munich

The personalized view is shown when users interact with City Pulse display. The users can make a request according to their preferences, for example, highlight all Japanese restaurants, or request to highlight the locations of their friends. The requests can be done by means of a mobile client. The requests can include price category, music style, non-smoking places, etc. Since such preference-based highlights are relevant only for the current requesting spectators, they appear only by demand, on the personalized view. Below we describe the solution we chose for the visualization of City Pulse display. 
The standard view of City Pulse shows the downtown map in black and white. The location of the user (and the display) is marked with a contrast magenta icon. Colored spots, overlaid on the map, depict the context data obtained from the citizens.

Density of people inside the location is mapped to the size of the colored spot: the smaller the spot, the less density inside. If the spot goes out of the building silhouette, the place is overcrowded.

Loudness is mapped to the opacity of the spot. The opacity of $100 \%$ corresponds to a very loud place, while $0 \%$ makes the spot almost invisible. Indeed, if the loudness is registered as zero, the place is absolutely empty and is probably closed. Thus, there is no need to display it on the map (Figure. 2 (left)).

Motion of people is presented by animation. Their activity reflects on the corresponding spot, i.e. if people are active (dancing), the spot pulsates with high frequency, on the contradictory, if they are standing the spot pulsates slowly.

The consumption of alcohol is encoded in color. A place with low alcohol consumption is depicted with a yellow spot. The redder the spot, the higher alcohol consumption (Figure. 2 (right)).
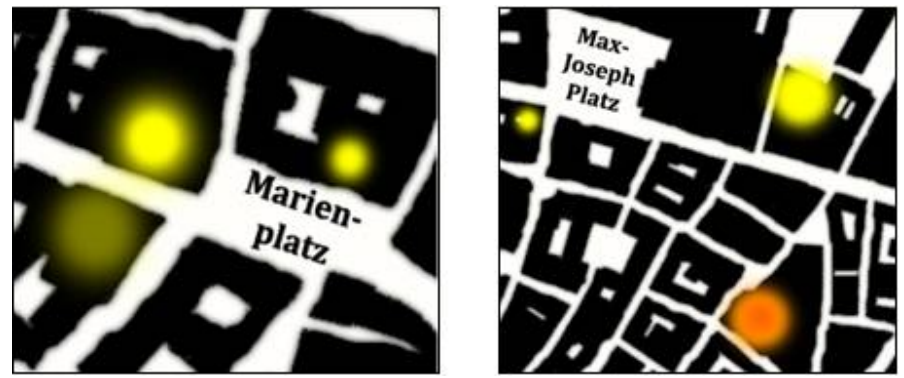

Fig. 2. Loudness is depicted by opacity of the spot (left), Alcohol consumption is encoded in color (right)

The personalized requests are shown with contrast magenta highlights. For instance, Figure 3 illustrates the request of Bavarian breweries in the downtown $\mathrm{Mu}-$ nich. Such highlights provide a quick overview of the necessary places. A request to highlight the locations of friends yields the display of colored dot. Each dot stands for one friend, hiding however any information on the friend's personality as illustrated in Figure 3.

\section{Conclusion and Future Work}

We presented the concept and design of City Pulse display, an urban public display which supports people in their going-out activities. The design of City Pulse was guided by the user study conducted as interviews with 20 international participants. The interviews inspired the design solution of City Pulse. We described the visualization design of the system. 


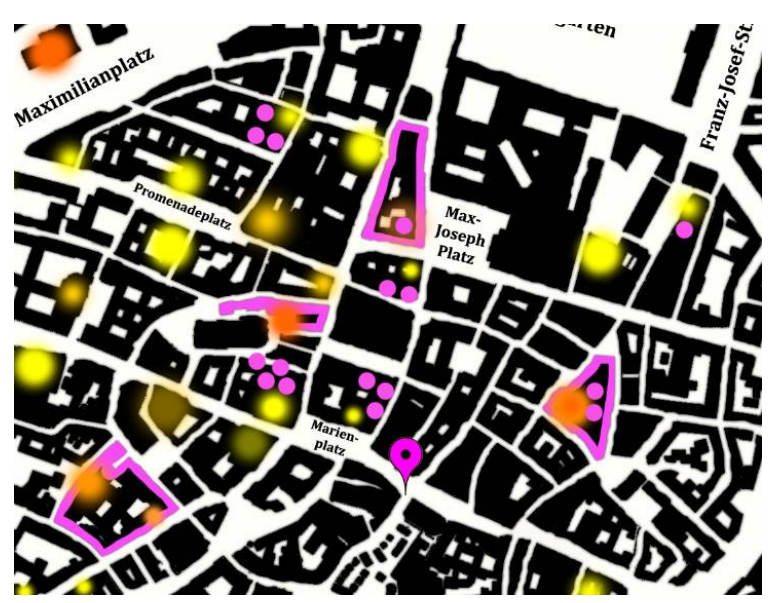

Fig. 3. Example of locations that match a personalized request and friends' locations

Future directions are put towards conducting a user evaluation of the presented concept to validate its use in public. In addition, we plan to integrate a recommender system that may initiatively propose locations based on the user's previous going-out history, the preferences of the user, and/or the preferences of their friends. The recommender system can also consider the environmental context, such as the weather, events in the city and daytime. Thus, in a cold winter day the display would rather propose cozy cafés, and in a hot summer evening - an opened terrace or a beer garden. Finally, the recommender system may take into account the emotional and social context. For example, it would propose a loud social place with many friends inside, when the user is sad and alone; or a romantic place when the user is happy, accompanied by their partner.

\section{References}

1. O'Reilly, T.: What is Web 2.0? Design Patterns and Business Models for the Next Generation of Software (2005), http://www.oreillynet.com/pub/a/oreilly/ tim/news/2005/09/30/what-is-web-20.html

2. Goodchild, M.F.: Citizens as voluntary Sensors: Spatial Data Infrastructure in the World of Web 2.0. International Journal of Spatial Data Infrastructures Research 2, 24-32 (2007)

3. Ratti, C., Pulselli, R.M., Williams, S., Frenchman, D.: Mobile Landscapes: Using Location Data from Cell Phones for Urban Analysis. Environment and Planning B 33(5), 727-748 (2006) 